\title{
Proposta de alternativa de traçado para uma nova linha do sistema VLT na cidade do Rio de Janeiro conectando o Aeroporto Internacional Tom Jobim ao centro da cidade ${ }^{1}$
}

\section{Proposal of an alternative route for a new line of the LRV system in the city of Rio de Janeiro connecting the Tom Jobim Internacional Airport to the city center}

\author{
Carvalho, Priscila Regina Damasio' \\ 1 Universidade Federal do Rio de Janeiro, Rua Nilton Santos 1355 bloco 3 \\ apartamento 503, Brasil, priscilacarvalho@poli.ufrj.br
}

\begin{abstract}
RESUMO
Diante dos diversos problemas que a cidade do Rio de Janeiro sofre com relação à mobilidade urbana, o presente trabalho tem o objetivo de contribuir com melhorias ao sistema de transporte público coletivo da cidade, a partir da apresentação de propostas de expansão do seu sistema de Veículo Leve sobre Trilhos (VLT). O estudo realizado foi um trabalho de final de curso de graduação em Engenharia Civil na Universidade Federal do Rio de Janeiro, e os resultados encontrados são parciais, sendo ainda necessários mais estudos. Foi realizada uma revisão bibliográfica sobre o sistema VLT, para compreender como ele surgiu, quais são suas características e onde já é implantado no Brasil e no exterior. Foi realizado também um estudo de caso em que verificou-se, a partir de entrevistas, que $34 \%$ dos passageiros que embarcam ou desembarcam no Aeroporto Internacional Tom Jobim tem como origem ou destino bairros da Zona Sul da cidade, e dessa parcela, somente um pequeno percentual de $36 \%$ utilizam como meio de deslocamento o transporte público coletivo. Foi, então, proposta uma alternativa de traçado para uma nova linha VLT, suprindo essa demanda e aproveitando seu potencial de regeneração urbana para desenvolver urbanisticamente áreas degradadas da cidade.
\end{abstract}

Palavras-chave: Mobilidade urbana, Transporte público, Sistema VLT, Regeneração urbana.

\begin{abstract}
Due to several problems that the city of Rio de Janeiro suffers in relation to urban mobility, the present work has the objective to propose improvements to the collective public transportation system of the city, from the expansion of its Light Rail Vehicle (LRV) system. The study was an end-of-course work in Civil Engineering at the Federal University of Rio de Janeiro, the results are partial and more studies are necessary. A bibliographic review about the LRV system was made to understand how it was born, what are its characteristics and where it is already implanted in Brazil and around the world. A case study was made in which it was verified, from

\footnotetext{
${ }^{1}$ CARVALHO, Priscila. Proposta de alternativa de traçado para uma nova linha do sistema VLT na cidade do Rio de Janeiro conectando o Aeroporto Internacional Tom Jobim ao centro da cidade. In: II SIMPÓSIO NACIONAL DE GESTÃo E ENGENHARIA URBANA: SINGEURB, 2019, São Paulo. Anais... Porto Alegre: ANTAC, 2019.
} 
interviews, that $34 \%$ of the passengers that arrive or leave the Tom Jobim International Airport have as origin or destination districts of the South Zone of the city, and of that portion, only a small percentage of $36 \%$ use collective public transportation. An alternative route was proposed for a new VLT line, supplying this demand and taking advantage of its urban regeneration potential to develop the urbanism of degraded areas of the city.

Keywords: Urban mobility, Public transportation, LRV system, Urban regeneration.

\section{INTRODUÇÃO}

\subsection{Contextualização}

A rede de transportes da Região Metropolitana do Rio de Janeiro compreende os sistemas de trens, metrô, barcas, VLT, BRT, ônibus intermunicipais, ônibus municipais e vans regulares. De acordo com as pesquisas realizadas no ano de 2012 para o Plano Diretor de Transporte Urbano da Região Metropolitana do Rio de Janeiro (PDTU-RMRJ), constatou-se que $77 \%$ das viagens por transporte coletivo são realizadas pelo ônibus, que é um modo de transporte de baixa capacidade não sustentável, como mostra a figura 1. O sistema de Veículo Leve sobre Trilho, mais conhecido como VLT não foi representado no gráfico, pois o início da sua operação foi em 2016, e as pesquisas datam de 2012.

Figura 1 - Distribuição percentual das viagens/dia por modo de transporte

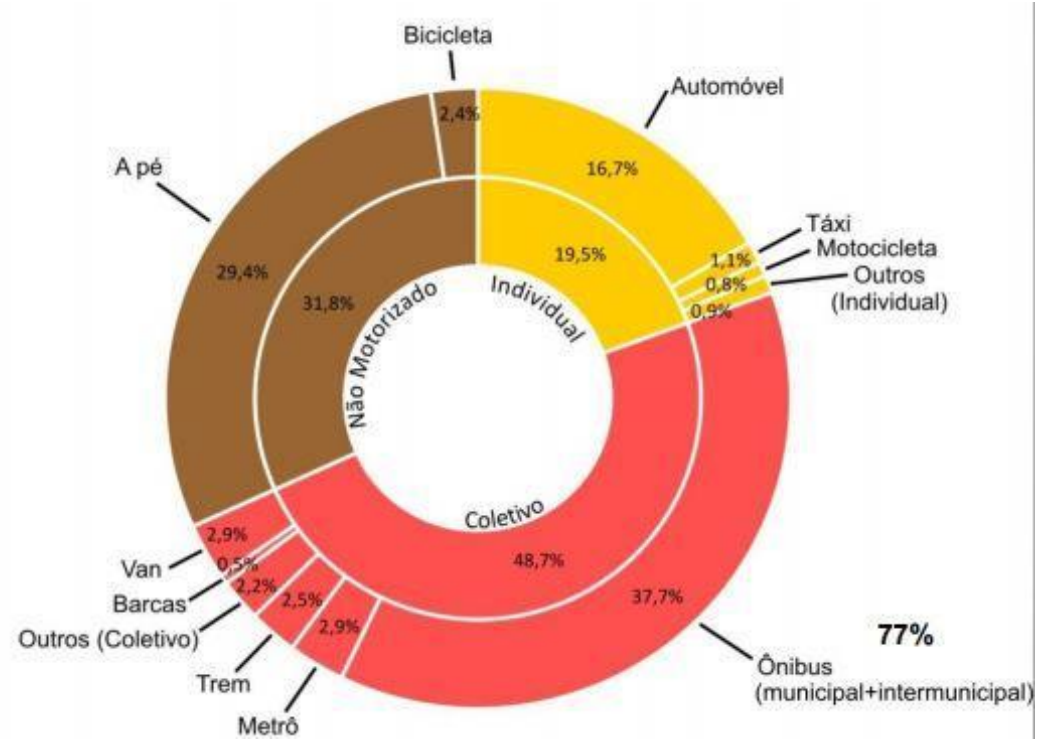

Fonte: PDTU, 2013

\subsection{Objetivos}

Visando melhorar a estrutura do transporte público coletivo da cidade do Rio de Janeiro, para tornar o sistema mais sustentável, integrado e com uma maior abrangência dos meios de média e alta capacidade, esse trabalho tem como objetivo apresentar uma proposta de traçado para um novo trecho do sistema VLT. O novo trajeto proposto irá conectar o Aeroporto Internacional Tom Jobim à Estação Central do Brasil, a qual já é uma estação das linhas 2 e 3 do VLTCarioca, na tentativa de reduzir o número de viagens por transporte individual e por ônibus.

\subsection{Justificativa}

Para chegar ou sair do Aeroporto Internacional Tom Jobim localizado no Rio de Janeiro, as opções de transporte oferecidas aos passageiros seguem o mesmo panorama apresentado 
para o restante da cidade, sendo o ônibus ou automóvel os principais meios. Como mostram as figuras 2 e 3, há um gargalo na rede de transporte pública da RMRJ entre o aeroporto e o centro da cidade, ficando evidente a dificuldade em chegar ou sair do aeroporto por meios de transporte público. Assim, os passageiros acabam por optar pelos táxis ou até mesmo automóvel próprio, corroborando para piorar tanto os congestionamentos como a polvição sonora e atmosférica.

Figura 2 - Rede de transportes da RMRJ indicando a região do estudo de caso

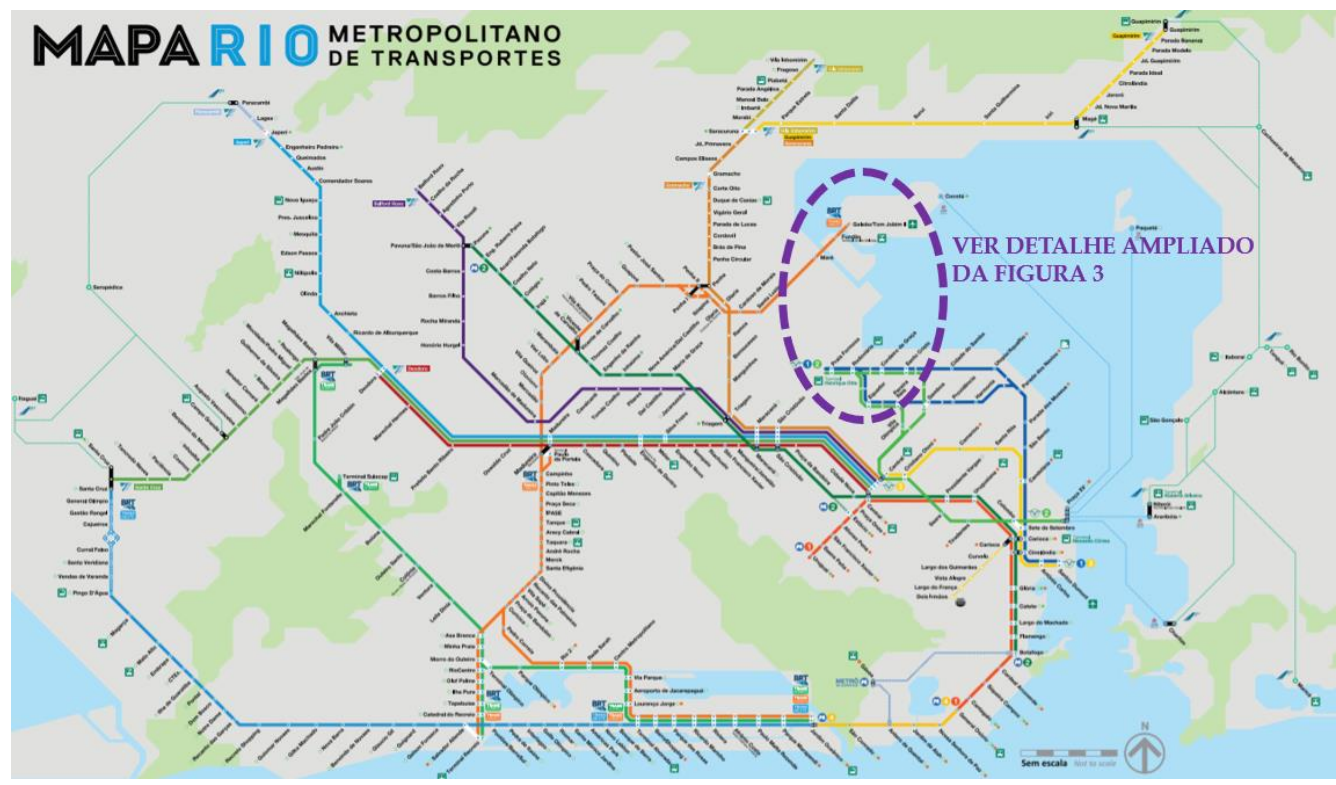

Fonte: GOVERNO DO ESTADO DO RIO DE JANEIRO adaptado pelo autor, 2019

Figura 3 - Detalhe da região do estudo de caso

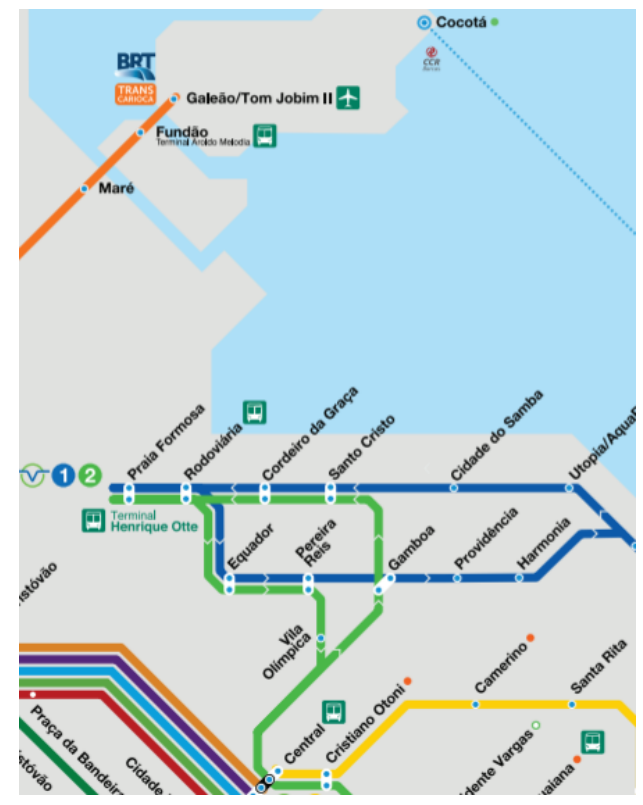

Fonte: GOVERNO DO ESTADO DO RIO DE JANEIRO adaptado pelo autor, 2019

\subsection{Metodologia}

A metodologia deste trabalho consiste na realização de uma revisão bibliográfica em artigos, livros e sites sobre mobilidade urbana, os diferentes tipos de transporte público coletivo 
oferecido no Rio de Janeiro, as características do sistema VLT e análise de sistemas internacionais já em funcionamento.

Além disso, foi feito um estudo de demanda a partir da realização de entrevistas, coletando dados sobre o volume de passageiros dependentes de transporte público na região em estudo e coletando também opiniões a respeito da atual condição de transporte.

\section{Principais características do sistema VLT}

O VLT por ser classificado como um sistema de média capacidade, capta e distribui os passageiros para os modais de maior capacidade e até mesmo proporciona uma capilaridade na rede de transporte das grandes cidades (CCR, 2012). É um sistema de veículos sobre trilhos que pode ser movido a combustíveis como diesel, álcool e gás natural veicular ou à eletricidade, essa força motriz elétrica atribui a esse sistema a característica de ser um transporte sustentável reduzindo a polvição sonora e do ar (ANPTrilhos, 2016).

O sistema de alimentação elétrica do VLT via catenária com cabos aéreos é o convencional que todos os fabricantes oferecem, mas há sistemas alternativos seja a partir do uso de baterias e capacitores ou a partir de alimentação pelo solo (APS). A vantagem desses sistemas alternativos é que dispensa a fiação suspensa, favorecendo a integração urbana e preservando a paisagem do entorno como por exemplo em zonas históricas. Além disso, há também uma boa integração com os outros veículos e pedestres pois muitas vezes circulam em zonas centrais onde há um tráfego intenso de veículos e grande circulação de pessoas (CCR, 2012).

O VLT é apontado como um sistema de transporte que tem a função não só de promover a mobilidade sustentável, mas também de induzir a revitalização de zonas urbanas degradadas, pois traz mais dinamismo para o comércio local a partir do momento que atrai mais pedestres e ciclistas diferentemente do ônibus, e também proporciona uma valorização imobiliária do entorno. De acordo com a ANPTrilhos (2016), na cidade de Freiburg na Alemanha houve uma valorização de $15 \%$ a $20 \%$ dos imóveis situados nas proximidades do trajeto do VLT. Além disso, o design moderno dos veículos do VLT contribui para 0 embelezamento da cidade estimulando a renovação da região (MOTTA, 2013).

Portanto, o VLT oferece um serviço de transporte com alta qualidade operacional proporcionando conforto, segurança, pontualidade, acessibilidade, além de reduzir a polvição e promover o reordenamento urbano, contribuindo para uma mobilidade urbana sustentável e inclusiva.

\section{Estudo de Caso}

\subsection{Localização}

A figura 4 mostra os principais locais por onde a nova linha do VLT poderia circular. Com essa proposta ligaria o aeroporto do Galeão à estação Central, aproveitando o trecho já existente da linha 2 do VLT entre a estação Rodoviária Novo Rio e a estação Central. Essa ligação com a estação Central é importante, pois é uma estação intermodal de integração dos sistemas VLT, trem, metrô e ônibus municipais e intermunicipais, possibilitando que o passageiro que chegue ao Galeão vá até ela e lá escolha qual modal é mais adequado de acordo com seu destino.

No trajeto, O VLT poderia passar também pela llha do Fundão onde está localizada a Universidade Federal do Rio de Janeiro, que é um pólo gerador de viagens, e também carece de transporte público coletivo. 
Figura 4 - Mapa mostrando os principais pontos por onde circularia a nova linha do VLT

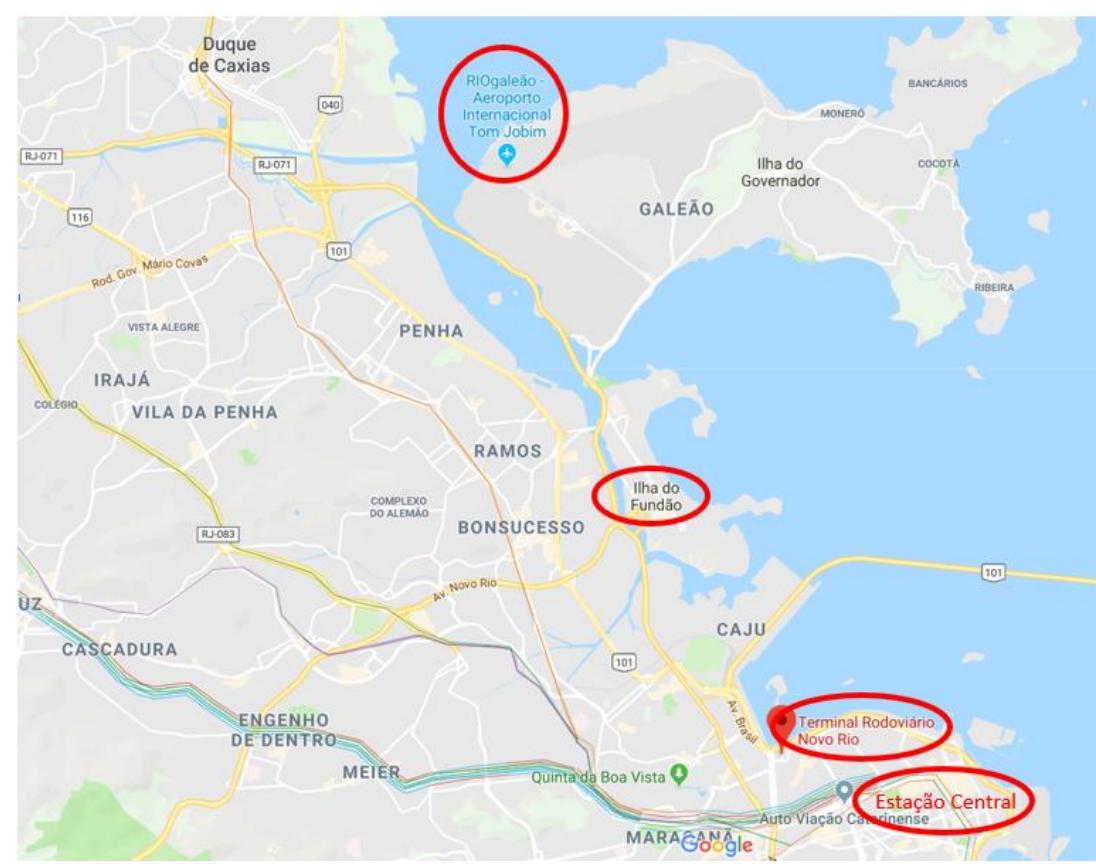

Fonte: GOOGLEMAPS adaptado pelo autor, 2019

\subsection{Análise da situação atual de transporte no Galeão}

Foram realizadas setenta entrevistas, a passageiros que estavam chegando ou saindo do Galeão. Constatou-se que $52 \%$ dos entrevistados utilizaram veículo próprio, táxi ou uber como meio de transporte para chegar ou sair do Galeão, como mostra a figura 5. Alguns alegaram que não conheciam formas de se deslocar por meio de transporte público coletivo, outros alegaram que a relação custo-benefício dos meios existentes não compensa e por isso preferem pagar um táxi ou uber pela segurança e comodidade. Essa parcela elevada do transporte individual evidencia a deficiência do transporte público coletivo no aeroporto, tanto pela falta de informação como pelo baixo nível do serviço ofertado.

Figura 5 - Percentual de viagem para cada modal

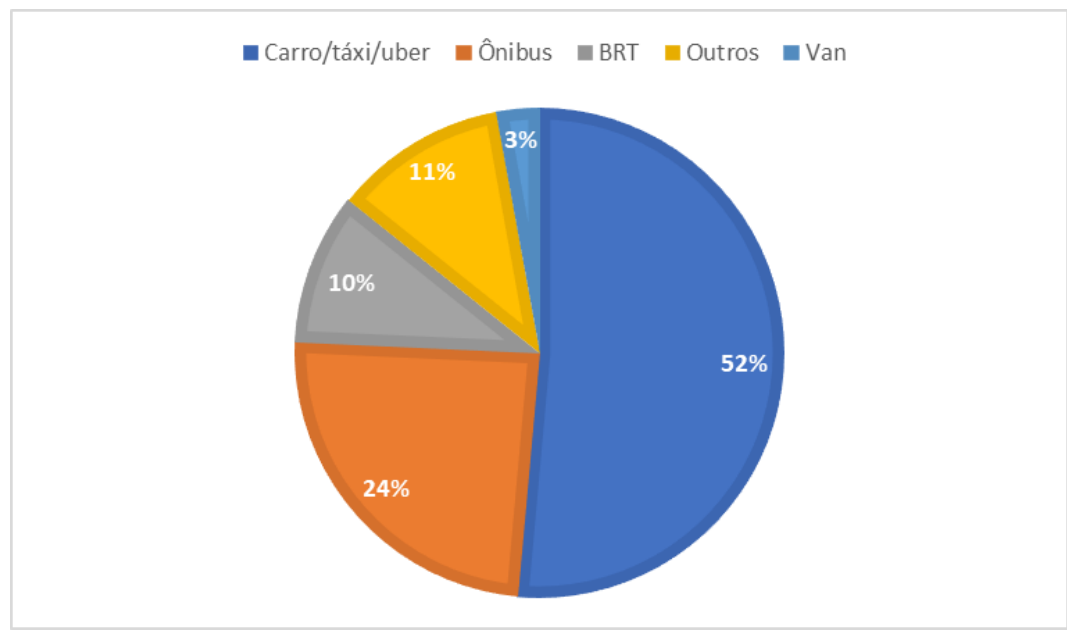

Fonte: A autora

Foi constatado que a maior parte dos entrevistados tem como origem ou destino bairros da Zona Sul, principalmente Copacabana, Ipanema e Leblon, totalizando $34 \%$ das viagens, conforme mostra a figura 6. 
Figura 6 - Percentual de viagens para cada zona

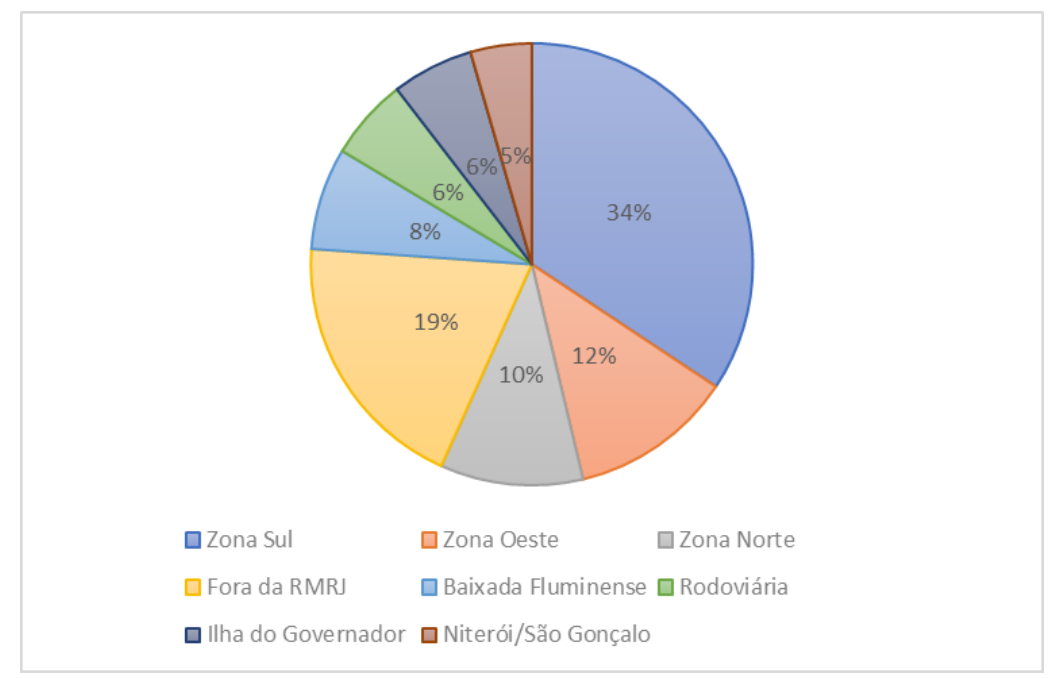

Fonte: A autora

A partir da figura 7, é possível notar que somente $36 \%$ das viagens desse trecho entre 0 Aeroporto e a Zona Sul são realizadas por transporte público coletivo, a partir da única linha de ônibus existente (linha 2018 premium), que custa $\mathrm{R} \$ 17$. Considerando que é a zona de maior atração turística da cidade e com maior porcentagem de viagens, deveria proporcionar uma melhor acessibilidade aos turistas que precisam chegar ou sair do Galeão por meio de outro modal de transporte que não o ônibus.

Durante as entrevistas, muitos turistas alegaram que optam pelo transporte individual, pois não se sentem seguros em pegar ônibus. Outros entrevistados, que não eram turistas, alegaram que além do tempo elevado durante o percurso, a tarifa dessa linha de ônibus é alta e deveria haver outra opção de transporte mais barata.

Figura 7 - Percentual de viagens com origem ou destino na Zona Sul

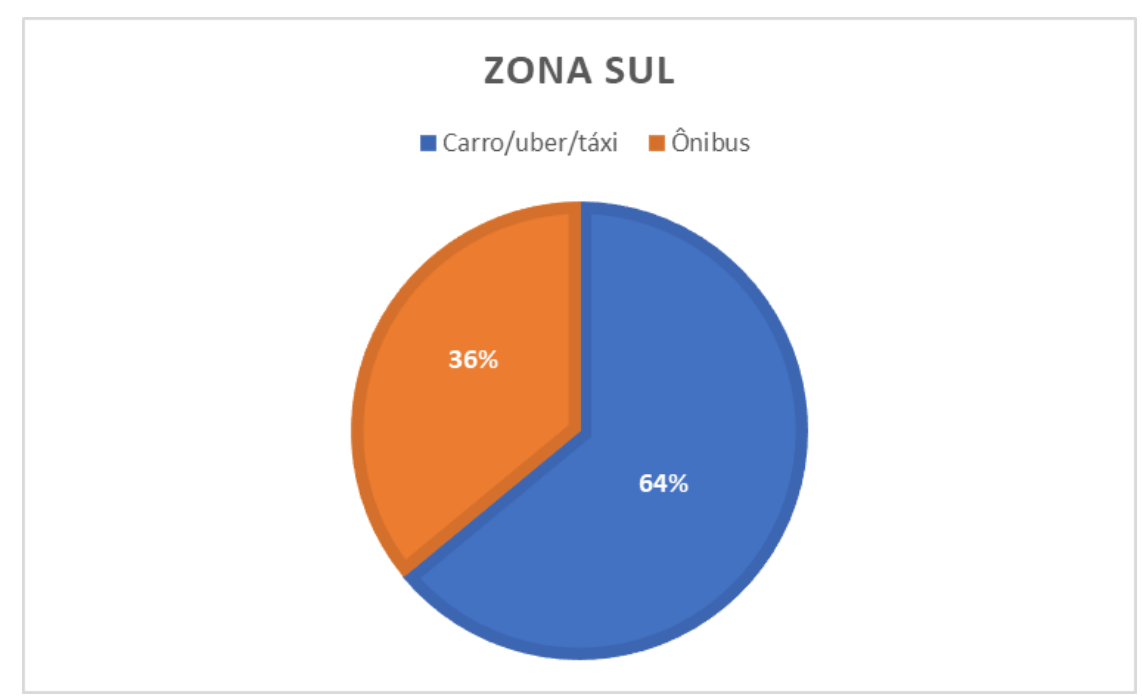

Fonte: A autora

Logo, a nova linha do VLT poderia suprir essa demanda por viagens mais baratas e seguras entre a Zona Sul e o Galeão. Essa ligação não seria feita de forma direta, necessitando de uma baldeação entre dois sistemas ferroviários. O passageiro pegaria o VLT até a Estação Central, realizaria a integração com o sistema metroviário seguindo para o bairro desejado, visto que a rede de metrô atende de forma satisfatória os bairros da zona sul da cidade. 


\subsection{Proposta de traçado}

A figura 8 ilustra uma possibilidade de traçado para essa nova linha do VLT. O trajeto em marrom se refere ao trecho da linha 2 já existente e o trajeto em vermelho se refere a nova proposta.

Figura 8 - Proposta de itinerário para nova linha do VLT

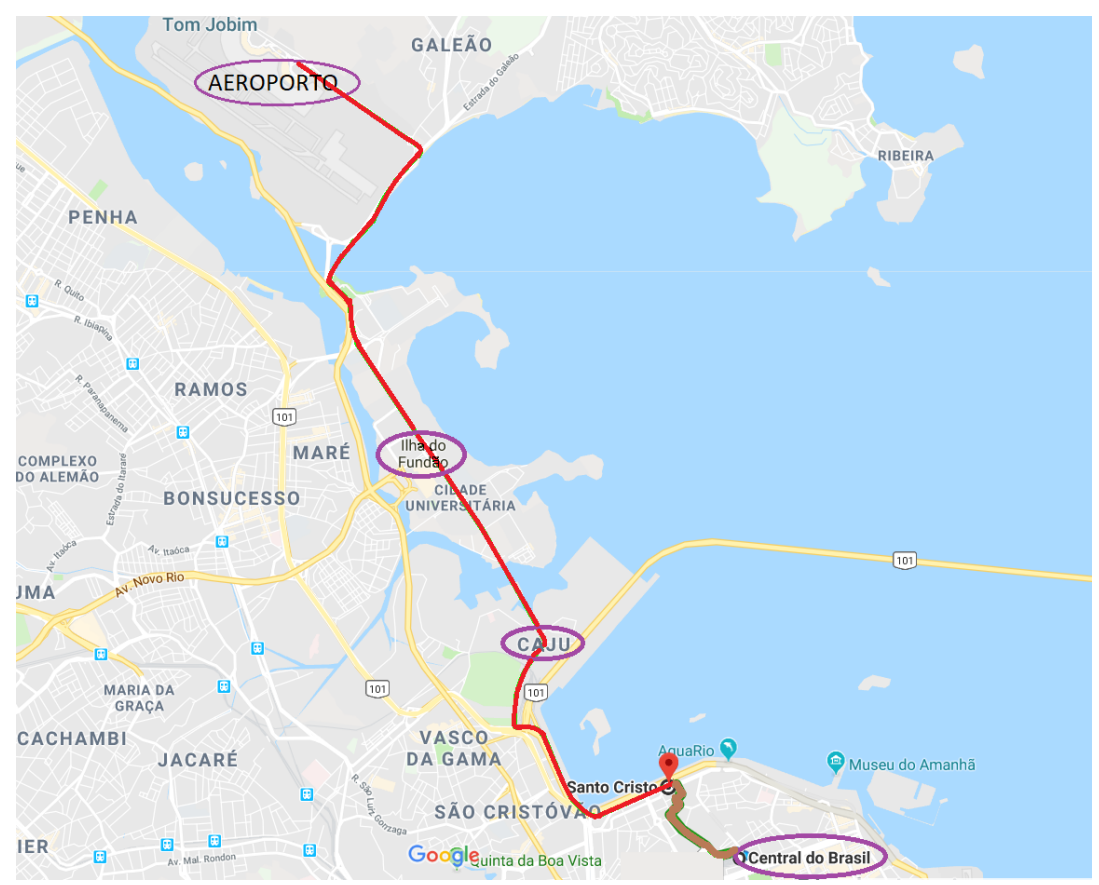

Fonte: GOOGLEMAPS adaptado pela autora, 2019

É importante destacar o caráter revitalizador dessa proposta para o bairro do Caju. Esse bairro, assim como os bairros da Gamboa, Santo Cristo e Saúde, cerceia a região portuária do Rio de Janeiro. Estes sofreram abandono e degradação com a evolução das técnicas portuárias, se tornando bairros vazios e que não acompanharam o ritmo de modernização da cidade. A partir da circulação dos veículos modernos do VLT com eletrificação ao nível do chão, as ruas do bairro ganhariam uma imagem mais moderna sem a poluição visual das catenárias, incentivando também a instalação de novos comércios, serviços e moradias. Além disso, o VLT incentivaria a circulação de pedestres e ciclistas, devido sua boa interação com eles, trazendo maior vitalidade para as ruas e proporcionando um espaço urbano integrado.

Apesar dos aspectos positivos com relação a menor interferência no trânsito da cidade e a regeneração urbana proporcionada, há aspectos negativos nessa proposta também. Será necessário realizar desapropriações no bairro do Caju, principalmente no trecho para construir a ponte para a llha do Fundão, local onde há uma comunidade. Essa questão irá elevar consideravelmente os custos dessa proposta, além de gerar transtornos sociais para os moradores que ali vivem e precisarão se mudar.

\section{Considerações finais}

Uma rede de transporte é capaz não só de promover deslocamentos, mas também de influenciar a forma urbana daquela região por onde passa. Essa nova linha do VLT proposta cumpre, então, essas duas funções: tornar os deslocamentos da rede de transporte público coletivo mais eficientes e integrados e promover o desenvolvimento de um espaço urbano mais sustentável e integrado.

A primeira função está relacionada ao fato de haver uma demanda por um transporte público seguro e com preço mais acessível no trecho entre o Aeroporto Internacional Tom Jobim e as zonas Sul e Central da cidade. O sistema VLT seria uma forma de proporcionar um 
transporte mais barato, com conforto e segurança, e ainda integrado com o sistema de trens e metrô.

Já a segunda função tem relação com a força de requalificação urbana do VLT e o itinerário proposto. A nova linha do VLT poderá contribuir para desenvolver urbanisticamente de maneira sustentável o atual bairro degradado do Caju devido a imagem moderna do bonde, sua baixa emissão de ruído e polventes atmosféricos e sua boa interação com pedestres, ciclistas e outros veículos.

\section{REFERÊNCIAS}

ASSOCIAÇÃO NACIONAL DOS TRANSPORTES DE PASSAGEIROS SOBRE TRILHOS (ANPTrilhos). VLT - Mobilidade Sustentável. 2016. Disponível em: <https://anptrilhos.org.br/wpcontent/uploads/2016/10/VLT-Mobilidade-Sustentavel.pdf> Acesso em: 25 out. 2018.

CCR. Estudo Preliminar e Provisório de Implementação do Veículo Leve sobre Trilhos na Região Portuária e Centro do Rio de Janeiro. Rio de Janeiro, 2012. Disponível em: < http://www.portomaravilha.com.br/conteudo/estudos/estudo_tecnico_preliminar_vlt_ccr.pd f> Acesso em: 04 jan. 2019

MOTTA, Marcio Wixak Vieira. O Veículo Leve Sobre Trilhos: Considerações sobre seus atributos como justificativa para a sua implantação, Dissertação de Mestrado, Programa de Engenharia Urbana, Universidade Federal do Rio de Janeiro, 2013. 